\title{
Energy systems in the context of sustainable development
}

Meza, Maria Josefina Figueroa; Roy, Joyashree; Urge-Vorsatz, Diana; Kahn Ribeiro, Suzana

\section{Published in:}

Current Opinion in Environmental Sustainability

Link to article, DOI:

10.1016/j.cosust.2013.05.001

Publication date:

2013

Document Version

Publisher's PDF, also known as Version of record

Link back to DTU Orbit

Citation (APA):

Meza, M. J. F., Roy, J., Urge-Vorsatz, D., \& Kahn Ribeiro, S. (2013). Energy systems in the context of sustainable development. Current Opinion in Environmental Sustainability, 5(2), 136-140.

https://doi.org/10.1016/j.cosust.2013.05.001

\section{General rights}

Copyright and moral rights for the publications made accessible in the public portal are retained by the authors and/or other copyright owners and it is a condition of accessing publications that users recognise and abide by the legal requirements associated with these rights.

- Users may download and print one copy of any publication from the public portal for the purpose of private study or research.

- You may not further distribute the material or use it for any profit-making activity or commercial gain

- You may freely distribute the URL identifying the publication in the public portal 


\section{Energy systems in the context of sustainable development Editorial overview Suzana Kahn Ribeiro, Joyashree Roy, Diana Urge-Vorsatz and Maria Figueroa}

\author{
Current Opinion in Environmental Sustainability \\ 2013, 5:136-140 \\ For a complete overview see the Issue \\ Received 3 February 2012; Accepted 23 April 2012 \\ Available online 30th May 2013 \\ 1877-3435/\$ - see front matter, (C) 2013 Elsevier B.V. \\ All rights reserved. \\ http://dx.doi.org/10.1016/j.cosust.2013.05.001
}

\section{Suzana Kahn Ribeiro}

Engineering Graduate Institute (COPPE), Federal University of Rio de Janeiro (UFRJ), Rio de Janeiro, Brazil

e-mail: suzanakr@gmail.com

Suzana Kahn-Ribeiro is a Professor at the School of Engineering Graduate Institute (COPPE), Federal University of Rio de Janeiro (UFRJ) Brazil. She is the Vice Chair of Working Group III of the IPCC Intergovernmental Panel on Climate Change, President of Scientific Committee of Brazilian Panel on Climate Change and 'ad hoc' consultant for the Brazilian Research and Development Council. She acted as lead author in the Fourth Assessment IPCC-2007 Nobel Peace Prize winning panel. Presently she is the Sub Secretary of Green Economy of Rio de Janeiro State Government. She also worked at the Brazilian Federal Government as the National Secretary of Climate Change at the Ministry of Environment.

\section{Joyashree Roy}

Jadavpur University, Department of Economics, Global Change Programme, 188 Raja, S.C. Mallik Road, Kolkata 700032, India

Joyashree Roy is a Professor of Economics, coordinator of the Global Change

Programme and Director of Ryoichi

Sasakawa Young Leaders Fellowship Fund (SYLFF) Project at Jadavpur University in Kolkata, India. She is a Coordinating Lead Author in the Fifth Assessment Report of the Intergovernmental Panel for Climate Change IPCC, and was lead author in the Fourth Assessment IPCC-2007 Nobel Peace Prize winning panel. She was also Coordinating author in one chapter of the Global Energy Assessment. She is interested in multidisciplinary approaches to understanding development challenges. Her research interests are economics of climate
This is the second special issue of Current Opinion in Environmental Sustainability focusing on Energy Systems. The issue is dedicated to provide an interdisciplinary overview of energy end-use and services in the context of Sustainable Development with attention to the wider notion of human wellbeing, social and gender implications, and related policy and institutional agendas. The section follows the first special issue on Energy Systems [1] being inspired by the recently completed international study Global Energy Assessment (GEA) [2] which demonstrated that energy systems need to be and $c a n$ be transformed to support a sustainable future; GEA established a state of the art assessment of the major challenges and transformations needed in the prevailing energy systems to sustain goals of prosperity and human wellbeing, goals that have been articulated and institutionalized in specialized agencies of the United Nations and restated in forums and discussions within the international community, most recently in the Planet Under Pressure [3] and Rio + 20 [4].

Energy is central to cope with major concerns of the 21st century such as equitable economic development, human wellbeing, health risks and damages, environmental pressures such as indoor and outdoor air pollution, energy independence, access, global energy security and additionally climate change. Identification of constraints and critical analysis of opportunities are important to find solutions. Through it's long journey humanity progressed by finding solutions to problems encountered or predicted. Humanity is now at a juncture to solve the question: can long run economic growth be sustained with growing constraints on local and global environmental services and within planetary boundaries? In a spatially fragmented world investments that add value to local and global resource need to be resolved by paradigm shifts in multiple directions of technology, policy, institutions and governance to expedite the desirable actions for sustainability transition.

One intrinsic challenge of energy for sustainable development is how to meet the increasing demand for energy services and under which fuel architecture will it be structured. Efficient energy services that meet the demand from buildings, transport and final energy users need to meet Sustainable Development goals and reach a global equitable provision. There is need for enabling environment to facilitate rapid transformation of current energy system with substantial benefits in all sectors of society and to help achieve necessary changes in culture and lifestyles. Keeping in mind the predicted population growth and aspiration for living with dignity, better living space and mobility in newly growing economies are expected to drive 
change, modeling energy demand, economy-wide modeling exercises for deriving policy implications, water quality demand modeling, water pricing, sustainable development indicator development and estimation, natural resource accounting, valuing environmental services, and developmental and environmental issues relevant for informal sectors, and coastal ecosystem service evaluation. She has worked extensively with developing country data.

\section{Diana Urge-Vorsatz}

Center for Climate and Sustainable Energy Policy, Department of Environmental Science and Policy, Central European University, Nador u.9, 1051 Budapest, Hungary

Diana Urge-Vorsatz is Director of the Center for Climate Change and Sustainable Energy Policy (CSEP) at the Central European University (CEU) in Budapest and Professor at CEU's Department of Environmental Sciences and Policy. She has worked on and directed several international research projects for organizations such as the European Commission, the European Parliament, the Global Environment Facility, United Nation's Environment Programme, the World Energy Council, Climate Strategies and the World Bank, and is a regular advisor of the Hungarian government. She is acting as a Coordinating Lead Author for the Fifth Assessment Report of the Intergovernmental Panel on Climate Change (IPCC) and acted in the same role for both the Global Energy Assessment and the 2007 Fourth Assessment Report of the IPCC, for the latter of which she has been acknowledged to have contributed to the Panel's Nobel Peace Prize. She was a member of the United Nation's Special Expert Group on Climate Change and has been serving on many international (strategic) advisory boards, including the Austrian Climate and Energy Fund, the UK Energy Research Centre, and the Scientific and Technical Advisory Panel of the Global Environment Facility, among others. She is Associate Editor of the Journal 'Energy Efficiency', and serves on the Editorial Board of 'Annual Reviews of Environment and Resources'.

\section{Maria Figueroa}

Technical University of Denmark, Department of Transport, Bygningstorvet 116B, DK-2800 Kgs. Lyngby, Denmark

Maria Josefina Figueroa is Assistant Professor in Sustainable Transport Energy Pathways and Urban Planning and Politics at the Danish Technical University, Denmark. She is a lead author in the Fifth Assessment Report of the Intergovernmental Panel for Climate Change and shared the coordinating energy demand. Justice demands faster provision of modern energy sources. How to meet this demand without adding to climate change risks is a major challenge of coming decades.

The articles in this issue are chosen keeping in mind the possible disciplinary diversity in readership covering social, political and natural science perspectives. As the original inspiration for this volume comes from the GEA, many of the papers are led by its lead authors restating, updating and further elaborating on selected key messages of the GEA; complemented by invited articles on subjects that complete the section's picture on a sustainable energy system transition focusing on an end-use perspective. Content diversity has been managed in such a way that researchers can get a status review of a branch of knowledge and identify the research gaps that can add value through future research. Policy makers can get useful tools and information from around the world helpful to decide on a course of action with sustainability goal. Overall, the articles can be grouped within three main areas on energy systems for global sustainability:

The first area identifies challenges and strategies for increasing the quantity, quality and efficiency of energy services for buildings and passenger transport in a long-term sustainable perspective. This thematic area is represented in five papers:

Urge-Vorsatz et al. update and reassess the findings related to the building sector in the GEA report focusing on the key challenges that energy use in buildings poses to environmental sustainability and demonstrating that if today's state-of-the-art technological and systemic solutions become standard practice, building thermal energy use can decline by as much as a third as compare to its 2005 by 2050; whereas without sufficiently ambitious performance levels embraced by policies, there is a significant lock-in risk, comprising as much as $80 \%$ of 2005 building thermal energy demand levels by 2050 . Besides improved energy efficiency the paper's scenario comparison indicates that strategic long-term vision, emphasis on building-integrated renewables as well as behavior, lifestyle and culture can take the building sector far in reaching sustainable development objectives.

Figueroa and Kahn-Ribeiro review and expand the methodology introduced in the transport GEA chapter offering a systematic approach for assessing the interactions of energy policies for passenger transport with sustainable development goals. Moving in the direction of targets and goals for the provision of efficient, affordable and low carbon passenger transport services, while concurrently attending to development, equity, and environmental concerns requires multi-levels and multi-objective policy interventions. The authors review current scholarship and demonstrate the use of an assessment tool to identify significant policy and goals interactions. Specifically how advancing transport goals and targets collectively plot towards or away system goals for a sustainability transition. The tool's value is determined by each context opportunities and constraints. The tool can assist in the articulation of decision support knowledge, involvement of multiple actors and the overall assessment of progress in transport and energy for sustainable development.

Boza-Kiss et al. present quantitative and comparative information of the societal cost-effectiveness of policy instruments that can catalyze the wide adoption of energy efficient technological solutions in the building sector concluding that all the reviewed instruments have the potential to generate economic benefits and that a regularly updated comparative assessment of costs and benefits of alternative policies and their packages would be a 
role as Coordinating Lead Author in the transport chapter of the Global Energy Assessment. Her research interest combines the use of quantitative impact assessments (energy, environmental, social, economic, behavioral) with policy analysis and scenario building techniques to find synergies, constraints and integrative aspects of transport and energy for sustainable development. She has worked as a consultant for the World Bank, United Nations and Danida, the development assistance body of the Government of Denmark. She has been a contributor in several large Strategic Research Council funded projects in Denmark. She works extensively with developing country data related to transport and energy policy issues. useful help for most countries, because the evolution of future governance regimes for a more sustainable building energy consumption depends on the successful selection of the most appropriate and most cost-effective policies.

D'Agosto et al. compare investments, energy consumption, carbon emissions and operational costs of alternative fuels and conclude that the use of biodiesel and diesel-gas systems stands out in relation to reductions in $\mathrm{CO}_{2}$ emission when one considers initial investment, energy consumption and operational cost; also the use of hybrid-drive buses is a promising option, while the use of bio-ethanol, although expensive, is the best option to reduce $\mathrm{CO}_{2}$ emissions, and this is not the case for dedicated natural gas buses. In sum, the paper considers the most promising options applicable to bus transit in Rio de Janeiro, Brazil.

Figueroa et al. articulate a visioning exercise contrasting present and long-term perspective conditions for passenger travel in developing countries. The vision has the aim of attracting greater research focus, policy attention and raising the profile and priority around conditions necessary for achieving sustainability and climate mitigation goals. They conclude that major investments in cost effective, high capacity, energy efficient, rapid, affordable and integrated bus and other public transport services will be required to accommodate the expected surging passenger transport demand in developing countries with sustainable solutions. It requires that subsidies for fuels and new private motor vehicles are reduced, or re-oriented for financial incentives toward the most sustainable vehicles and modes of transport. That institutional capacity building for planning and policy implementation at all decision-making levels is improved and that the built environment offers safe pedestrians and non-motorized routes in a future where total passenger travel growth is reduced and accommodated far more with sustainable modes.

The second thematic area identifies challenges of changing human behavior to reduce energy demand and improve acceptability of new energy technologies. This area is elaborated in three papers:

Dowd and Hobman discuss the interventions that can most effectively motivate individuals and communities to use less energy and accept new energy efficient and alternative fuel technologies departing from the deep understanding among researchers that attitudinal change among citizens can deliver environmental good. They review a large number of the emerging literature emphasizing the importance of appropriate information generation and dissemination to bring in attitudinal change among citizens.

Haustein and Hanneke identify why and how intelligently strategized marketing principles might achieve changes at higher scale rather than trying one size fits all kind of strategy for diverse consumer categories. Identifying target groups can help faster penetration of environmentally sustainable transport. The paper reviews different segmentation approach and concludes that the area is under-researched but has high potential for value addition in terms of actions that might be taken to promote sustainable transport. The advantages of segmentation of population in meaningful target groups for acceptance of policies to reduce car use and other policies aiming at implementing environmentally sustainable transport need to be explored more.

Pachauri and Rao identify key gaps in current literature of understanding on a specific demographic group women and how their decision-making power, wellbeing outside or within the household relates to energy poverty; they then 
develop a compelling argument for the need to improve empirical evidence on the gender differentiated impacts of energy and as a determinants of energy poverty.

The third area covered in this issue relates to the identification of challenges to decision making and opportunities associated with the use of decision-support tools in relation to a sustainable energy end-use and services transformation. The area is covered by the following papers:

Chakravarty et al. provide an important review of the current debates and literature on the rebound effect. The literature that reflects enthusiasm over energy efficiency led decision making to achieve emission reduction need to consider that the effectiveness will depend on the magnitude of rebound effect. Theoretically the literature accepts the mechanism of rebound but its magnitude is debated. This exhaustive review shows the magnitude of rebound varies across sectors and across countries. The authors find there is limited evidence from developing countries but existing literature suggest that rebound is higher there due to unmet demand for energy services. In the context of long-term global sustainability issue this implies that justice would demand higher provision of energy in developing countries despite growing scaling up of efficient technology. Policy interventions need to be sensitive to country context

Cabeza et al. review embodied energy in materials and identifies it as a key issue for affordable building construction. The paper shows there is a lack of research about embodied energy and carbon in the context of buildings and construction materials and argues that comparison between studies is not possible due to the different assumptions used by the researchers, the focus in a given location, and the great variation between data presented in the embodied energy databases available. The paper concludes from the available studies on the significance of embodied energy in buildings materials and their implications concerning the affordability of building construction.

Chakraborty and Roy review practical examples from various country contexts and sector studies where estimates of carbon footprint have been advanced and reflect on the need to achieve a uniform methodology for these numbers to be of greater consequence toward low carbon choices. As a decision-making tool carbon and energy footprint provides an excellent tool toward making choices among alternative options, for example, between gas based power generation and oil, coal based power generation.

Goldstein et al. reflect on the gaps in existing decisionsupport tools and identify gaps in the information provided by assessment tools such as Building Environmental Assessment tools (BEAs), life cycle analysis (LCAs) and urban metabolisms, especially when authorities are confronted with large scales renovate versus rebuilt building decisions. They conclude that decision makers seldom integrate BEAs or standalone LCAs when considering renovate vs rebuild scenarios and even when used BEAs can result in suboptimal energy decisions either by performing incomplete LCAs or by ignoring key sustainability aspects in their frameworks. Effective management of the building stock is essential to reducing future building energy consumption, particularly in addressing the European aging building stock, $70 \%$ of which predates the mandating of thermal insulation after the 1970s energy crisis.

Santos and Kahn-Ribeiro review and select sustainable transportation indicators and use them subsequently to demonstrate the applicability of these indicators in monitoring progress toward the goals presented in the Climate Change Policy Plan for reducing greenhouse gas emissions of the state of Rio de Janeiro. They find that certain actions in this plan could not be monitored using sustainability criteria, indicating the importance of establishing monitoring criteria to measure the sustainability of transport in addition to the development of government plans and policies in this way establishing a process that can assist in decision making in the state of Rio de Janeiro, Brazil.

Roy et al. review documents the crucial role that fiscal instruments are playing toward inducing a low carbon energy transition. Low carbon transition can happen through policy induced incentives for technology penetration as fiscal instruments can create appropriate market forces to promote low carbon growth, can leverage private finance, and mobilize domestic finance to enhance effectiveness and efficiency. Locally adapted fiscal instruments can help sustainable system transition. This paper maps out the attempts that are creating evidence of the importance of fiscal instruments to sustain a low carbon transition worldwide.

While this issue does not attempt to cover a vast body of literature, the richness and comprehensiveness of the GEA, the collected papers bring together a set of issues which need further attention both for research and policy prioritization and that are of special significance to future sustainability of human wellbeing.

One common theme that comes out of these review articles is that voluntary reporting; voluntary actions both by private sector actors and governments have positively demonstrated the steps to be followed in scaling up success stories. They also demonstrate the extent of the existing data gaps, and how the absence of appropriate capacity of the various actors at different levels, for example, companies, countries, constrain full estimation and comparability of key decision parameters. Faster, reliable and sustained context- 
based knowledge generation and dissemination is one of the urgent tasks to catalyze the transformation toward a more sustainable future from an energy end-use perspective.

Finally, an interesting aspect of this issue, from a sustainable development perspective, is that all of its lead authors, as well as a large majority of its other contributing authors, are women. They come from five continents, and span many ethnicities and religions. While the diversity represented by these authors has been mostly incidental, it does demonstrate that there are many highly qualified female thinkers all around the world ready to influence academic and policy discourses at the highest levels in the field of sustainable energy transformations. Unfortunately despite the efforts of the editors it was not possible to secure female authors from Africa, reinforcing the much discussed need for further capacity building in this continent also in the field of sustainable energy end-use transformation discourses. Despite this weakness, we believe that this diversity in geographic, ethnic and religious origins in the issue's authorship, combined with an emphasis on women among the authors, provides a unique focus and blend of perspectives - ones that are less often exposed in the academic literature but that crucially complement the mainstream.

\section{References}

1. Pachauri S, Cherp A: Energy security and energy access: distinct and interconnected challenges. Curr Opin Environ Sustain 2011, 3:199-201.

2. GEA: Global Energy Assessment - Toward a Sustainable Future. Cambridge, UK/New York, NY, USA/Laxenburg, Austria:

Cambridge University Press/The International Institute for Applied Systems Analysis; 2012, :. Available from www.globalenergyassessment.org (Internet)

3. Leemans R: Global-change research to understand, handle and solve problems of a Planet under Pressure. Curr Opin Environ Sustain 2012, 4:1-2.

4. United Nations Conference on Sustainable Development: The Future We Want. United Nations Conference on Sustainable Development; 2012. 